\title{
La Trinidad en la oración, según S. Agustín'
}

Pío DE Luis VizCAÍNO

RESUMEN: El obispo de Hipona establece diversos tipos de relación tanto de una de las personas divinas como de la Trinidad en cuanto tal con la oración cristiana. El presente artículo se fija solo en el segundo caso: la Trinidad es contemplada como destinataria de la oración, como objeto de alabanza, de deseo y de petición, y como receptora de la oración.

PALABRAS CLAVE: Trinidad, oración, deseo.

ABSTRACT:The Hipona bishop establishes diverse types of relation so of one of the divine persons as the Trinity as such with Christian prayer. This article focuses only on the second case: The Trinity contemplated as the destination of the prayer, like objet of praise, of desire, and request, and like recipient of the prayer.

KEYWORDS: Trinity, prayer, desire.

\section{Introducción}

Entre los títulos honoríficos otorgados a san Agustín se cuentan el de doctor de la Trinidad y el de doctor de la gracia. A este último título va asociado el de doctor de la oración ${ }^{2}$, dado que la necesidad de la gracia arras-

\footnotetext{
${ }^{1}$ Este artículo es complementario al que aparecerá publicado con el título La dimensión trinitaria en la oración en san Agustín, en F. MANS y otros, La oración cristiana, oración trinitaria: testigos y maestros (Semanas de Estudios Trinitarios, 45), Secretariado Trinitario, Salamanca 2012, pp. 91-131. La introducción que sigue aquí es la misma que en el artículo indicado.

${ }^{2}$ Según palabras de A. Trapé, "Sant'Agostino è il grande dottore della preghiera, perché ha messo in luce il nesso inseparabile tra la grazia, la preghiera e la legge divina" (SANT'Agostino, la Preghiera, Lettera a Proba e Commento al Padre nostro. Introduzione di Agostino Trapè, Città Nuova, Roma 1995, p. 5 (lema).
} 
tra consigo la necesidad de la oración. ¿Cómo armonizó el santo doctor la fe en la Trinidad y la praxis orante del fiel cristiano? Del hecho no cabe dudar en principio. Si alguna época dejó claro que la teología es la vida espiritual traducida a conceptos o que la espiritualidad es la teología hecha vida, esta fue la patrística, con san Agustín como uno de sus más cualificados representantes. No en vano el teólogo hiponense pasa por ser, con razón, uno de los grandes orantes ${ }^{3}$. La teología estaba lejos de ser pura ciencia especulativa y los teólogos de profesión aún no habían aparecido.

No conocemos ninguna monografía sobre la relación entre oración y Trinidad en el obispo de Hipona. Siendo numerosos los estudios sobre su enseñanza acerca de la oración, la constatación hecha deja entender que esa relación no tiene una presencia deslumbrante, pues no parece haber suscitado excesivo interés en los estudiosos. Es cierto que en la bibliografía pertinente tocan el tema algunos autores ${ }^{4}$, pero también lo es que lo hacen de un modo sumario $^{5}$. El campo sigue abierto, pues, a una exploración más amplia.

La oración es práctica esencial de la existencia cristiana. Su fundamento último se halla en la creación del hombre por Dios a su imagen y

3 "En su inmediatez, en su profundidad y perseverancia, la vida de oración del gran Padre de la Iglesia, vida de alabanza y adoración, de glorificación y gratitud, de súplica y confesión, difícilmente halla comparación en la historia de la piedad cristiana. Agustín ha expresado en forma de oración cuanto de más elevado y más íntimo pueda un hombre decir a su Dios" (K. RUH, Storia della mistica occidentale. Vol I. Le basi patristiche e la teologia monastica del XII secolo, Milano 1995, p. 130).

${ }^{4}$ En su estudio Doctrina agustiniana de la oración, G. García Montaño dedica una apartado a "La oración y la Trinidad", pero limitándose a señalar lo que cada Persona divina en particular verifica en el dinamismo de su eficacia (cf. Augustinus 18 [1973] 179-302: 286-302). N. Cipriani dedica el cuarto capítulo de su obrita (La pedagogia de la preghiera in S. Agostino, Ed. Augustinus, Palermo 1984,35-42) a las dimensiones teologales de la oración cristiana, donde hace referencia al aspecto pneumatológico y al cristológico. También A. Solignac examina ambos aspectos de la oración según san Agustín (Dictionnaire de Spiritualité, XII,22632264). J. García Álvarez dedica un apartado a la oración y el misterio de la Trinidad, pero la presentación es muy breve y puramente deductiva, sin apoyo textual alguno (cf. Oración y conversión en san Agustín, en Revista Agustiniana 29 [1988] 547-592).

5 Otros no lo tocan. Por ejemplo, Paulino Sahelices (San Agustín, maestro de oración, Edit. Revista Agustiniana, Madrid 2003) y Antonio Sánchez Carazo (Mendigo de Dios. Agustín maestro de oración, México 1996). El primero piensa, sí, en el Hijo y en Espíritu Santo en el apartado titulado "Pensamientos sobre la oración", pero los referentes a estas dos divinas Personas se hallan perdidos, entre otros 23 temas, en los $n^{\text {os }} 10$ y 11 . El segundo tampoco tiene en cuenta el aspecto trinitario de la oración, aunque al hablar de su definición introduce un apartado titulado "La oración es un diálogo en el que el Espíritu santo nos ilumina", y en el modo de orar otro, con el título: "El Espíritu Santo, guía de la oración". Curiosamente no dedica ninguno a Jesucristo, aunque lo menciona, obviamente, al hablar del aspecto eclesial. 
semejanza (Gén 1,26-27), que san Agustín entiende como la capacidad del hombre de entrar en relación personal con Él, en clave trinitaria. En efecto, el hombre no es imagen de Dios porque se acuerda, se comprende y se ama a sí mismo, sino porque puede acordarse de su creador, comprenderlo y amarlo. Y la oración hace efectiva esa capacidad, pues es en sí misma memoria de Dios, contemplación de Dios y expresión de amor a Dios. Por eso, al concluir su obra magna sobre la Trinidad, el santo le eleva esta oración: "Haz que me acuerde de ti, te comprenda, te ame"6.

En la oración entran siempre en juego tres factores: el sujeto que la hace, el destinatario que la recibe y el contenido de la oración misma. Este contenido la diversifica en oración de alabanza y petición, por indicar sólo las dos formas más presentes en los textos agustinianos?.

A su vez, la trinidad de personas y la unidad de esencia o naturaleza son datos esenciales que circunscriben el misterio del Dios cristiano. Ha sido una constante atribuir a san Agustín el haber iniciado la corriente teológica predominante en occidente que, partiendo de la unidad de naturaleza, llega a la Trinidad de personas, opuesta a la de oriente que, partiendo de la Trinidad de Personas, desemboca en la unidad de naturaleza. Pero estudios de los últimos tiempos han mostrado que tal juicio es erróneo y que el santo es un representante más de la antigua tradición cristiana que daba la preferencia a la consideración de la Trinidad de Personas sobre la unidad de esencia ${ }^{8}$. Ahora cabe preguntarse si esta perspectiva teológica queda reflejada en la enseñanza agustiniana sobre la oración.

A primera vista podría parecer que no, pues en los textos agustinianos la oración aparece dirigida, de ordinario, a Dios, lo que haría pensar que va

${ }^{6}$ Cf. trin. $15,28,51$.

${ }^{7}$ Sobre el vocabulario referente a ambas formas de oración, cf. M. VINCENT, Augustin et le vocabulaire de la prière, en Augustiniana 41 (1991) 783-804. Aunque el estudio se limita a las en. Ps., sus resultados son, en conjunto, válidos para toda la obra, salvo en parte los datos estadísticos.

${ }^{8}$ En palabras de F. Berrouard: "Ya no se puede, pues, sostener más que es su concepción del misterio la que ha conducido a los escolásticos a colocar el tratado De Deo uno antes del De Deo trino" (La Trinité est le seul Dieu, BA 75, Paris 2003, pp. 475-478: 478). El autor aporta abundantes textos del conjunto de la obra agustiniana en apoyo de lo afirmado. Cf.. en la misma dirección, B. STUDER, La teologia trinitaria in Agostino d'Ippona. Continuità della tradizione occidentale?, en pp.161-177. Esta realidad tiene un reflejo en la antropología: mientras en las primeras obras el santo tiende a hablar de la naturaleza humana entendida como imago Dei, en De Trinitate trata de comprender cómo el ser humano es imago Trinitatis (cf. B. MCGINN, Storia della mistica cristiana in occidente. Le origini (I-V secolo), Genova 1997, p. 330, que remite a J. E. Sullivan, The image of God:The Doctrine of St. Augustine and its Influence, Priory Press, Dubuque, Iowa, 1963). 
destinada directamente al Dios único y no a una u otra de las divinas Personas. Pero hay que tener en cuenta la base bíblica y tradicional del modo de expresarse del santo. En sus textos, "Dios" designa en sentido propio (proprie) al Dios de Israel y al Padre de Jesucristo, el Padre todopoderoso del Símbolo de la fe, el sentido específico de la Biblia y también de la Liturgia; en otro sentido (communiter), proveniente de la tradición cristiana y, sobre todo, de la reflexión a que dio origen la lucha antiarriana, el término puede designar a Jesucristo, al Espíritu Santo y a la entera Trinidad ${ }^{9}$. Así, pues, para saber a qué Persona divina se eleva la oración en cada caso, es necesario descubrir la concreción prosopológica del título "Dios". Lo ordinario es que el santo se refiera con él al Padre, aunque en determinados casos entienda como concretado en Jesucristo el "Dios" o Señor al que invoca el salmista ${ }^{10}$.

Algo parecido ha de decirse a propósito del título "Señor". Cuando se trata de textos veterotestamentarios, lo normal es que el santo lo interprete como referido al Padre. Un caso a parte lo constituyen los salmos, pues la lectura cristológica que hace de ellos le permite referirlo también a Jesucristo. No siempre, pues su misma interpretación según la cual muchos de sus versículos son oración de Cristo por la Iglesia, presupone que el Señor es Dios Padre ${ }^{11}$. Los textos del Nuevo Testamento aplican el título a Jesucristo que, una vez resucitado, fue constituido Kyrios (Hch 2,36), aunque no siempre, dado que el mismo Jesús llama "Señor" a su Padre (cf. Mt 11,25). Y a este uso bíblico se atiene san Agustín. Los textos escriturísticos con que el santo acompaña su oración y su mismo contenido permiten dilucidar en cada caso concreto a qué Persona divina se está dirigiendo. Por otra parte, sea que, en contexto de oración, el santo refiera o aplique los títulos "Dios" y "Señor" al Padre, sea que los refiera o aplique Jesucristo, o al Hijo encarnado en Jesucristo, siempre hay que entenderlos en el marco de su teología trinitaria, a la que pertenece, junto a la unidad de esencia o naturaleza y trinidad de Personas, el principio de su inseparabilidad en las obras ad extra.

${ }^{9}$ Cf. B. Studer, Gratia Christi - gratia Dei bei Augustinus von Hippo. Christozentrismus oder Theozentrismus?, SEA 40, Roma 1993, pp. 283-285; del mismo autor, La teologia trinitaria in Agostino d'Ippona. Continuità della tradizione occidentale?, en Cristianessimo e specificità regionali nel mediterraneo latino (sec. IV-VI). XXII Incontro di studiosi dell'antichità cristiana, Roma, 6-8 maggio. SEA 46, Roma 1994, 161-177:167-168.

${ }^{10}$ Cf. En. Ps. 67,2. Otros ejemplos en K. Baus, Die Stellung Christi im Beten des heiligen Augustinus, en Trierer theologische Zeitschrift 63 (1954) 321-339: 327.

11 Cf. M. Fiedrowicz, Psalmus vox totius Christi. Studien zu Augustins "Enarrationes in Psalmos", Herder, Freiburg im Breisgau 1997, pp. 242ss. 
Un mínimo conocimiento de la obra de san Agustín permite concluir que la Trinidad no es objeto de particular devoción para él y, a la vez, que la Trinidad es inseparable de su doctrina sobre la oración. No es objeto de particular devoción si se piensa en una devoción como, por ejemplo, la Devoción a la Divina Misericordia, o Devoción de los primeros viernes de mes. Entrar por esta vía significa hacer un recorrido, más que corto, nulo. El mundo de las devociones particulares no había hecho aún su aparición en la piedad del pueblo cristiano. La Trinidad no entra en la oración agustiniana como una opción en competencia con otras. Por otra parte, si la vida cristiana en su conjunto es inconcebible sin la dimensión trinitaria, también lo ha de ser una práctica tan esencial como la oración. De hecho, la oración aparecía vinculada a la Trinidad ya en la misma iniciación cristiana. Tal como se desarrollaba en Hipona, la catequesis sobre el Padrenuestro, la traditio orationis, seguía sin solución de continuidad a la catequesis sobre el Símbolo de la fe, la traditio symboli, conforme a la pauta marcada por san Pablo en Rom 10,14: ¿Cómo invocarán a Aquel en quien no han creído? El Dios al que debían elevar su oración los que iban a ser bautizados no era otro que el Dios Trinitario del Símbolo que el obispo les había expuesto previamente ${ }^{12}$. Es cierto que en la exposición agustiniana del Padrenuestro a los catecúmenos no se encuentran referencias tan nítidas a la Trinidad como en sus antecesores africanos Tertuliano ${ }^{13}$ o san Cipriano ${ }^{14}$, pero no lo es menos que, al exponerles el Símbolo, el santo les había explicado ya quién era el Padre al que iban a orar, y no sentía necesidad de repetirlo ${ }^{15}$. Lo que exponía a los competentes en la traditio orationis no era un modelo, entre otros, de oración, sino la misma oración cristiana en su realidad más auténtica.

12 El santo explica el orden en la catequesis con estas palabras: "primero el símbolo con el cual podréis saber qué tenéis que creer, y luego la oración con la cual podréis saber a quién habéis de invocar" (s. 56.1).

${ }^{13}$ De oratione 9,3: "Ś́lo de Dios podía venirnos el culto ordenado en la oración. Esta, proferida por sus (del Hijo) divinas palabras y como animada por su Espíritu, por su gracia sube al cielo y recomienda al Padre lo que el Hijo nos ha enseñado". Y previamente: "Con el título 'Padre' se invoca al mismo tiempo al Hijo, pues él dijo: Yo y el Padre somos una misma cosa (Jn 10,30)" (ib. 2,5). En la misma línea se mueve Orígenes en el primer comentario al Padrenuestro que conocemos en lengua griega (De oratione, 5 ).

${ }^{14}$ De dominica oratione, 2: “¿Pues qué oración más espiritual puede haber que la que nos fue dada por Cristo, por quien nos fue enviado el Espíritu santo, y qué plegaria más verdadera ante el Padre que la que brotó de labios del Hijo, que es la Verdad?". El mismo san Agustín, en su comentario al Padrenuestro dentro del comentario al Sermón de la montaña, señala que la misma gracia por la que somos coherederos con Cristo y poseemos el Espíritu de adopción, es la que nos hace llamar "Padre" (s. dom. m. 2,4.16).

${ }^{15}$ Cf. s. $212,213,214$. 
La dimensión trinitaria de la oración cristiana está siempre sobreentendida, pero no siempre hecha explícita. Y cuando el santo la hace explícita, la motivación que le guía es preferentemente teológica, pero también espiritual. O toma pie de determinados datos de la enseñanza bíblica sobre la oración para afianzar planteamientos doctrinales, o lo toma de los planteamientos doctrinales para instruir sobre la oración. Lo iremos viendo en las páginas que siguen.

Hay dos formas de referirse al misterio central de la fe cristiana: o utilizando el término Trinidad que incluye a las tres divinas Personas -la Trinidad es el único y verdadero Dios-, o enumerando por separado las distintas Personas que la constituyen -el Padre, el Hijo y el Espíritu Santo son el único verdadero Dios-. Examinadas ya las diversas relaciones con la oración que san Agustín asigna a cada Persona divina por separado ${ }^{16}$, procede examinar ahora las que establece nominalmente con la Trinidad o con las tres divinas Personas en conjunto.

\section{La Trinidad y la oración cristiana}

El obispo de Hipona contempla la Trinidad como destinataria de la oración, como objeto de deseo, como objeto de súplica y como receptora benévola de la súplica de los fieles.

\section{a) La Trinidad, destinataria de la oración}

La única razón para introducir este apartado es la existencia de una doxología trinitaria: “A este Dios, a saber, al Padre, al Hijo y al Espíritu santo, a la Trinidad que es un único Dios, el honor y la gloria por los siglos de los siglos"17. Es el único caso de alabanza a la Trinidad que hemos encontrado en la obra agustiniana. Es poco, pero es algo. En cambio, no hemos detectado ninguna otra oración ni de acción de gracias, ni de petición dirigida

${ }^{16}$ En el artículo a que hemos hecho referencia en la nota $\mathrm{n}^{\circ} 1$.

${ }^{17}$ C. Max. 2,12,2: "A este Dios, a saber, al Padre, al Hijo y al Espíritu santo, a la Trinidad que es un único Dios, el honor y la gloria por los siglos de los siglos". Las doxologías trinitarias, aunque no solo trinitarias, eran bien conocidas en la oración cristiana de los tres primeros siglos. Cf. al respecto, A. HAMNAN, La oración: I. El Nuevo Testamento. II. Los tres primeros siglos, Barcelona, Herder 1967, pp. 680-682, 572, 639, 750, 756; también (cf. Oraciones de los primeros cristianos. Selección de A. Hamman, O.F.M e Introducción de DanielRops, Ediciones Rialp, Madrid 1956, nn. 50, 52, 59, 68, 80, 94, 98, 98ª , 101, 156, 157, 159, 160, $165,173,178,289)$ 
nominalmente a la Trinidad o al conjunto de las tres divinas Personas. Es más, lo que bien podía haber formulado como súplica, el santo prefiere expresarlo en forma de deseo: "Que la Trinidad nos libre de la multitud de pecados"18. Significativamente, la oración que pone término al tratado $L a$ Trinidad, está encabezada con "Señor Dios nuestro", aunque inmediatamente es especificado como Padre, Hijo y Espíritu Santo ${ }^{19}$. Es el mismo proceder que encontramos en un texto de las Confesiones en que el santo invita su fe a proseguir en su confesión ${ }^{20}$. Sin embargo, no duda en invocar a la Trinidad sirviéndose de conceptos abstractos, como en el conocido texto de la misma obra: " $¡ O$ Oh eterna verdad, verdadera caridad y amada eternidad"21. Como dirigida a la Trinidad suele contarse la oración que da inicio a sus Soliloquios, una de las más bellas de la antigüedad cristiana ${ }^{22}$, pero su estructura parece más ternaria que propiamente trinitaria ${ }^{23}$. En la más célebre de todas, la obra Las Confesiones, se repiten estructuras ternarias ${ }^{24}$, pero no cabe entenderla como oración trinitaria.

${ }^{18}$ S. 213,7. La súplica expresada en forma de deseo aparece ya en san Pablo, cuando escribe en 2 Cor 13,13: "La gracia del Señor Jesucristo, la caridad de Dios y la comunión del Espíritu Santo estén con todos vosotros".

${ }^{19} \mathrm{Cf}$. trin. 15,28,51. También es significativo que anteponga la cita de Mt 28,19 que funda la trinidad de Personas (Mt 28,19) a la de Dt 6,4 que funda la unidad divina.

${ }^{20}$ Conf. 13,12,13: "Prosigue en tu confesión, fe mía. Dile al Señor tu Dios: santo, santo, santo, señor Dios mío. En tu nombre hemos sido bautizados, Padre, Hijo y Espíritu Santo. En tu nombre bautizamos, Padre, Hijo y Espíritu santo". Dios es invocado como Unidad y Trinidad a la vez en Conf. 12,7,7: "Deus, una Trinitas et trina unitas".

${ }^{21}$ Conf. 7,10,16. Y ello aunque pudiera tener inspiración porfiriana. Cf. G. MADEC, Les Confessions comme prière biblique, en Lectures augustiniennes, Paris 2001, 111-119: 113. En Io. eu. tr. 97,1, la terna, claramente referida a la Trinidad, la constituirán la eternidad, la verdad y la santidad.

${ }^{22}$ Cf. P. DE LaBriolle, en Bibliotèque Augustinienne 5, Bruges, DDB 1948, p. 401.

${ }^{23}$ Cf. D. DoucET, Recherche de Dieu, Incarnation et Philosophie: Sol I, 1, 2-6, en Revue des Études Augustiniennes 36 (1990) 91-119, que informa sobre los estudios que le han precedido, con interpretaciones diferentes: trinitaria la de unos (A. Solignac, O. du Roy, J. Verhees), no trinitaria la de otros (F. Cavallera, J. Doignon). El autor propone una lectura menos trinitaria y más soteriológica y cristológica, algo que correspondería mejor a las preocupaciones de Agustín en ese período de su vida. Posteriormente a él, B. Studer rechaza su carácter trinitario (cf. Gratia Christi, p. 157), mientras que G. Madec la considera ciertamente trinitaria, aunque de manera discreta y voluntariamente encubierta (cf. Le Dieu d'Augustin, Cerf, Paris 2000, pp. 70-71).

${ }^{24} \mathrm{C}$. Starnes defiende que la estructura de las Confesiones es trinitaria. Según el autor, en los libros 1-9, en que se dirige a todos los hombres, san Agustín confiesa su relación al Padre; en el décimo, en que se dirige a los hermanos en la fe, la relación al Hijo; y en los tres últimos, en que se dirige a los hombres espirituales, la relación al Espíritu Santo. Esta triple confesión daría razón del título, en plural, de la obra: Confesiones. La misma estructura trinitaria regula internamente, además, cada una de las tres partes. Estas, en efecto, se hallan di- 
Esta actitud restrictiva puede explicarse desde la Escritura, la Liturgia y la tradición. La Escritura no contiene ninguna invocación dirigida nominalmente a la Trinidad, término que ignora, ni al conjunto de las tres divinas Personas en comunión entre ellas ${ }^{25}$; en cuanto a la liturgia, le cerraba el camino el concilio de Hipona al ordenar que en la celebración eucarística todas las oraciones se dirigiesen al Padre ${ }^{26}$; la tradición tampoco le ofrecía apoyo ${ }^{27}$.

Lo dicho puede ser explicación suficiente del actuar de san Agustín, pero se puede añadir algo más. Como teólogo eminente de la Trinidad, siempre tiene presentes los dos principios ya señalados: la unidad de esencia o naturaleza de las tres divinas Personas y la inseparabilidad de las mis-

vididas, a su vez, en otras tres secciones en que aparece la relación con las otras dos personas, desde la perspectiva de la Persona asignada a dicha parte (cf. The Unity of the "Confessiones», en Studia Patristica XVIII,4 (1990) 105-111 [publicado en español, en Augustinus 31 (1986) 275-284]. Cf. también del mismo autor, The Place and Purpose of the Tenth Book of the Confessions, en Congresso (Roma 1986), Atti II, pp. 95,103; Augustine's Conversion. A Guide to the Argument of Confessions I-IX, Ontario 1990, p. XIV, n. 1). También K. Kinzler asigna a la obra una estructura formalmente trinitaria. Dado que Agustín confiesa en la obra a un Dios único, pero también trino, no debe sorprender -sostiene-, que haya asignado a las Confesiones una estructura ternaria/trinitaria. El origen de esta, sin embargo, no hay que verla sólo en la fe cristiana, sino también en la filosofía neoplatónica. El autor presenta una estructura diacrónica y otra sincrónica, ambas fuertemente marcadas en clave trinitaria (cf. Gott in der Zeit su berühren. Eine Auslegung der Confessiones des Augustinus, Würzburg 1998).

${ }^{25} \mathrm{El}$ apóstol Pablo se limita a iniciar sus cartas expresando un deseo con una fórmula binaria, referida a las personas del Padre y del Hijo: "Gracia y paz a vosotros de parte de Dios nuestro Padre y del Señor Jesucristo" (Rom 1,7; cf. también 1 Cor 1,3; 2 Cor 1,2; Gál 1,3; Ef 1,2; Fil 1,2; 1 Ts 1,1; 2 Ts 1,2; 1 Tm 1,2; 2 Tm 1,2; Tt 1,4; Fil 3, y asimismo 2 Pe 1,2; 1 Jn 1,3; 2 Jn 1,3). Sólo una vez, en la conclusión de la segunda Carta a los Corintios, se sirve de una fórmula ternaria: "La gracia del señor Jesucristo, el amor de Dios y la comunión del Espíritu Santo sean con todos vosotros" (2 Cor 13,13). Otra cosa es que, a pesar de todo, el teólogo Agustín descubra la Trinidad. La argumentación del santo puede verse en ep. Rm. inch. 1112. Cf. también las doxologías presentes en Ef 3,21 y 1 Pe 4,11.

${ }^{26}$ Cf. M. KlöCKENER, Das eucharistische Hochgebet bei Augustinus. Zu Stand und Aufgaben der Forschung, en Signum pietatis. Festgabe für Cornelius Petrus Mayer OSA zum 60. Geburtstag. Herausgegeben im Auftrag des Augustinus-Instituts der deutschen Augustiner von Adolar Zumkeller OSA, Augustinus Verlag, Würzburg 1989, pp. 467-473; cf. también, E. J. KILMARTIN, Early african Legislation concerning liturgical Prayer, en Ephernerides liturgicae 99 (1985) 105-127: 106-110.

${ }^{27}$ A. Hamman sólo constata un ejemplo de oración dirigida a la Trinidad en los tres primeros siglos y, además, de un autor griego, Clemente Alejandrino (cf. La oración, pp. 721-722, con referencia a Paedagogus 2,12,101). Entre las 364 seleccionadas por A. Hamman de textos de los cinco primeros siglos de la Iglesia, sólo aparecen dos invocaciones trinitarias, sumamente breves, provenientes de inscripciones egipcias (cf. Oraciones de los primeros cristianos. Selección de A. Hamman, O.F.M e Introducción de Daniel-Rops, Ediciones Rialp, Madrid 1956, nn. 123 y 124). 
mas en las obras ad extra. De uno y de otro se deriva que, donde se halla una Persona divina, se hallan también las demás y que, donde actúe una de ellas, la que sea, actúa la Trinidad, Dios único ${ }^{28}$. En el plano puramente teológico, es importante tener en cuenta que los términos con que se designan las Personas de la Trinidad aluden a relaciones que fundan su distinción personal. En razón de su existir relative, puesta una, están puestas las otras dos: "al mencionar una persona de la Trinidad, es menester sobrentender siempre las otras dos"29. En consecuencia, quien ora al Padre sabe que ora al Padre de Jesucristo y que quien ora a Jesucristo sabe que ora al Hijo del Padre, sin olvidar al Espíritu santo, Don de ambos. El pastor de Hipona llega hasta admitir la posibilidad de entender bajo el nombre "Padre" la Trinidad, aunque sea en sentido traslaticio y sólo en relación a la criatura por la adopción filial ${ }^{30}$.

\section{b) La Trinidad, objeto de deseo}

Según san Agustín, la oración de petición no tiene por objeto hacer conocer a Dios lo que el orante necesita, pues no puede ignorarlo. Cuando Dios manda orar, lo que pretende es que el fiel ponga en ejercicio su deseo, a fin de que se agrande y así se haga capaz de acoger lo que se dispone a darle ${ }^{31}$. Por tanto, si el objetivo de la oración de petición es activar el deseo, el mismo deseo aparece ya como sustituto de ella, razón por la que el santo lo considera como una forma de oración. Mediante el deseo, el fiel puede cumplir el precepto del Señor de orar siempre sin desfallecer (cf. Lc 18,1) o el apostólico de orar sin interrupción (1 Ts 5,17): "Si deseas siempre, oras siempre"32.

Para realizar su destino personal, el hombre precisa bienes de toda índole, incluidos los materiales. Pero, aunque los juzga necesarios, el pastor de Hipona recomienda no limitarse a ellos. El fiel ha de elevar de nivel el contenido de su deseo; en vez de ajustarlo a sus limitadas aspiraciones humanas, ha de adaptarlo a lo que Dios es capaz de dar ${ }^{33}$. Su ambición ha de ser proporcionada a la categoría del donante.

El destino último del hombre, aquello a lo que aspiran todos sin excepción, no es otra cosa que la felicidad. Si, en línea con la filosofía anti-

${ }^{28}$ Io. eu. tr. 94,5 .

${ }^{29}$ Cf. trin. $1,10,21$.

${ }^{30}$ Trin. 5,11,12. Esa posibilidad la excluye referida al Hijo y al Espíritu Santo

${ }^{31}$ Cf. ep. $130,8,17$.

32 S. 80,7; en. Ps. 37,14. Cf. N. AdKIn, Augustine, Sermon 80,7: Quando dormitat oratio, en Augustiniana 46 (1996) 61-66.

${ }^{33}$ Cf. en. Ps. 62,14 . 
gua $^{34}$, san Agustín repite como una cantinela que todo hombre desea ser feliz ${ }^{35}$, no extraña que ponga el objetivo de la existencia humana en la consecución de la vida bienaventurada. Que la felicidad del hombre radica en Dios es tema habitual en la reflexión agustiniana. Para el santo, la felicidad plena es inseparable de la adhesión a Dios y su posesión definitiva ${ }^{36}$.

El obispo de Hipona vincula explícitamente la felicidad a la Trinidad. La formulación más clara la ofrece en la obra La doctrina cristiana, manual de exégesis bíblica. Según su autor, la Sagrada Escritura contiene dos tipos de realidades: aquellas de que sólo se debe usar $(u t i)$ y aquella de la que se debe gozar (frui). Luego concreta: "La res de que se ha de gozar es el Padre, el Hijo y el Espíritu Santo, es decir, la misma Trinidad que es la única y más excelsa realidad y común a todos los que gozan de ella"37. A idéntica conclusión llega como teólogo cuando afirma: "Nuestro pleno gozo, mayor que el cual no hay otro, es gozar (frui) de la Trinidad", añadiendo luego la explicación: "a cuya imagen hemos sido hechos" 38 . La misma verdad trasmite en cuanto catequista, sea a los que se acercan por primera vez a la fe ${ }^{39}$, sea a los catecúmenos o a los fieles ${ }^{40}$. Apoyándose en el hecho de que la palabra púnica trinitas significa salud, identifica con la salud esa bienaventuranza ${ }^{41}$.

Igual que en las Confesiones el deseo de confesar a Dios lo suscita Dios mismo ${ }^{42}$, así el deseo de la Trinidad que impulsa el pedirla lo suscita la Trinidad misma. La Trinidad -dice el predicador de Hipona- desea corazones que la amen, otorgando también aquíi3 valor causativo al verbo desear: "Se dice acertadamente que desea, porque hace que el cristiano la desee" 44 .

${ }^{34}$ Cf. $s .150,4-5$;

${ }^{35}$ Ep. 130,9; en. Ps. 32,2,2,15-16;118,1,1; S. 53,1;231,5;306,3-4; s. Dolbeau 16,10; s. Mai 12,2, etc.

${ }^{36}$ Cf. ep. $155,2,8 ; 155,3,9.12 ;$ s. 231,$5 ; 306,7$.

${ }^{37}$ Doctr. chr. 1,5,5.

${ }^{38}$ Trin 1,9,18. Cf. también trin 3, pról, 2: "la Trinidad el único supremo y sumo bien".

${ }^{39}$ Cat. rud. 47: "Dios mismo será todas las delicias y la hartura de la ciudad santa que vive sabia y felizmente en él y de él, pues llegaremos a ser... iguales a los ángeles de Dios y juntamente con ellos gozaremos de aquella Trinidad en visión directa". Nótese el lenguaje alternativo: primero habla de Dios, luego de la Trinidad.

${ }^{40} S .51,34$ : "El número diez representa la perfección... de la felicidad, porque une a las criaturas hechas en siete días a la Trinidad del creador".

${ }^{41}$ Cf. ep. Rm. inch. 13.

${ }^{42}$ Conf. $1,1,1$.

${ }^{43}$ Asignar valor causativo al verbo es práctica habitual del santo cuando interpreta Rom 8,26 o Gál 4,9. Según él, san Pablo dice que el Espíritu intercede o clama por los fieles porque hace que ellos intercedan o clamen. Cf. Gen. c. Man. 1,22,34; ep.130,15,28; ep. 194,4,16; de an. et or. 4,9,13; c. s. arrian. 21,25; conl. Max. 13; c. Max. 1,9; perseu. 23,64; Io. eu. tr. 6,2; ep. 194,4,17; s. 71,29; corrept. 15,47.

${ }^{44}$ S.Dolbeau 22,7. 
Yendo más lejos aún, el santo convierte en deseo de alcance trinitario otros textos que, en su literalidad, tienen por objeto a una sola Persona divina. El deseo de Felipe de ver al Padre (Jn 14,8) ${ }^{45}$ lo transforma en deseo trinitario: "(Felipe) sólo deseaba al Padre, pero el Señor le indicó que debía desear tres panes" (cf. Lc 11,5), es decir, las tres divinas Personas ${ }^{46}$. Más explícitamente lo afirma en otro texto: "Como Felipe suponía que esa realidad $^{47}$ es el Padre solo y dijo: Señor, muéstranos al Padre y nos basta (Jn 14,8), el Señor le muestra que el fin es Dios, pero el Dios Trinidad"48. El deseo, convertido en súplica, de ver al Padre, lo transforma el predicador en deseo, que ha de acabar también en súplica como la de Felipe, de ver la Trinidad.

Los textos agustinianos unen tres conceptos: deseo, saciedad y Trinidad. La Trinidad representa la saciedad y el fin del deseo: una vez alcanzada la Trinidad, el deseo se ve saciado y, por eso mismo, llegado a su fin: ya no hay nada que desear. El "nos basta" no está solo en el conocer al Padre como creía Felipe; solo es verdad tras alcanzar la Trinidad. El santo, por otra parte, recuerda que tal saciedad no pertenece a esta tierra porque el alma no está capacitada para comer alimento tan sólido y grande. Esa capacidad solo la conseguirá tras una renovación profunda ${ }^{49}$, una vez que haya trascendido todo lo mutable, sea material o espiritual ${ }^{50}$.

${ }^{45}$ El predicador trae a colación este pasaje del evangelio de san Juan comentando el versillo 5 del salmo 102 (103): Sacia de bienes tu deseo, a propósito del cual ha introducido también los tres panes de la parábola del amigo importuno (cf. Lc 11,5-8).

${ }^{46}$ En. Ps. 102,10. Como buen conocedor de la Escritura y teólogo, el santo no encuentra la menor dificultad en descubrir la Trinidad en el texto juánico. Las dos primeras personas aparecen ya explícitas en el texto: "quien me ha visto a mí-el Hijo- ha visto también al Padre". Para introducir al Espíritu, recurre a otras palabras de Jesús algo posteriores que lo presentan como Espíritu del Padre y del Hijo: "A quien enviará el Padre en mi nombre" (Jn 14,26), y "A quien yo os enviaré en nombre de mi Padre" (Jn 15,26). En consecuencia, en cuanto Don de ellos, es inseparable de ambos. De aquí su conclusión: "Conocí qué he de desear, pero ¿cuándo me saciaré de ello? Ved que ahora discurro sobre la Trinidad". En la misma línea, aunque no tan completo, porque no integra al Espíritu formalmente, en. Ps. 45,1.

${ }^{47} \mathrm{El}$ santo viene hablando del fin "a donde queremos llegar, mantenernos estables, sin tener que buscar más" (s. Dolbeau 20,3).

${ }^{48} S$. Dolbeau 20,4

${ }^{49}$ Cf. s. Dolbeau 20,4; en. Ps. 102,10.

${ }^{50} \mathrm{Cf}$. $s$. Dolbeau 22,7. 


\section{c) La Trinidad, objeto de súplica}

Que el santo considere el deseo en sí mismo como oración, no impide la oración. Más aún, de ordinario el deseo acaba en oración que, precisamente, agranda el deseo, como indicamos. Si el hombre suele pedir lo que desea, porque lo necesita o simplemente porque le agrada, es lógico que el fiel que desea la Trinidad pida la Trinidad. Poco después de haber dicho que la Trinidad desea porque hace que el cristiano la desee, el predicador invita a pedirla: "(La Trinidad) nutre los corazones de quienes la desean, la aman con pureza, desinteresadamente, al no hallar nada que merezca ser amado más que ella. Y si hallan algo, tómenlo como su recompensa; si no, pídanla" 51 . En la hipótesis de que ella ${ }^{52}$ no quisiera darse como recompensa al fiel, este debería dedicarse a gemir sin tregua y renunciar a pedirle cualquier otra cosa. Pero no es el caso. Quien, renunciando a otras cosas, se eleva sobre toda criatura llegará a la contemplación de la Trinidad y beberá de la misma fuente de la que bebió san Juan ${ }^{53}$. El texto parafraseado contempla tres momentos: el del deseo, el de la petición y el del logro. En el centro está el pedir la Trinidad, impulsado por el deseo, suscitado por la Trinidad misma; como logro aparece la contemplación de la Trinidad, recompensa que ella misma ofrece.

Como el obispo de Hipona acostumbra a leer el Antiguo Testamento en clave neotestamentaria, los viejos textos adquieren para él nuevos significados. Así, los bienes con que el salmista deseaba saciarse (cf. Sal 102,5) ya no son caducos o temporales, sino eternos, la Trinidad santa, los tres panes que pedía el amigo de la parábola evangélica (cf. Lc 11,5-8) ${ }^{54}$. De igual manera, la única cosa que el salmista pedía al Señor (Sal 26,4) pasa a ser ahora el Dios Trinidad ${ }^{55}$. El versículo del salmo es presentado como ora-

${ }^{51} \mathrm{~S}$. Dolbeau 22,7.

52 Ahora la considera en su condición de creadora.

53 S. Dolbeau 22,7.

${ }^{54}$ En. Ps. 102,10: “El sacia tu deseo de bienes (Sal 102,5). ... No me saciaré de bienes mortales, no me saciaré de bienes temporales; que me done, que me conceda algo eterno; que me dé su Sabiduría, que me dé su Palabra, Dios junto a Dios, que se dé Dios, Padre, Hijo y Espíritu Santo. Soy un pobre que estoy ante su puerta; a quien estoy llamando no duerme; que me dé los tres panes".

55 Trin. 1,13,31. El salmista pide una cosa -habitar en la casa del Señor-para conseguir lo que desea -contemplar el deleite del Señor-. Habitualmente, el comentario de san Agustín se ciñe a las palabras del salmo. Pero en algún caso abandona la clave veterotestamentaria, que sólo conoce al único Señor, y pasa al Nuevo Testamento, en que se ha revelado ya la Trinidad: "El Dios que se manifestará para gozo de los elegidos es el Dios único, el Padre, el Hijo y el Espíritu Santo. Por este gozo futuro suspira el que dice: Una cosa he pedido al Señor, esta buscaré: habitar en la casa del Señor todos los días de mi vida, para contemplar el deleite del Señor". 
ción que el Espíritu, con gemidos inefables, pone en el corazón del fiel, cuyo resultado será la contemplación de la Trinidad, una vez que el mediador entre Dios y los hombres, el hombre Cristo Jesús, haya entregado el reino a Dios Padre ${ }^{56}$. El orante cristiano se ha apropiado la oración del salmista, pidiendo lo mismo que él, pero ya en la perspectiva trinitaria. El santo deja la librea de exegeta y viste la de teólogo. El Dios y Señor del Antiguo Testamento se ha manifestado en el Nuevo como Trinidad ${ }^{57}$. El deleite que el judío esperaba y que estimulaba su oración ya no es el del Señor, sino el del Dios trino ${ }^{58}$. Tras el Señor del salmista, el cristiano ve ya la Trinidad misma. La Trinidad es, en última instancia, el objeto único de la oración cristiana: unam petii ${ }^{59}$. Tras esa petición están los gemidos inefables del Espíritu ${ }^{60}$.

La parábola del amigo inoportuno es el texto bíblico que más clara y repetidamente inspira a san Agustín presentar a la Trinidad como objeto de la oración de petición. Una constante domina su exposición: ver simbolizada en los tres panes la Trinidad. Ella es lo que desea recibir el amigo inoportuno que solicita los tres panes ${ }^{61}$. Sólo en un texto manifiesta el santo cierta duda ${ }^{62}$; en los demás lo afirma sin titubeos.

Pero ¿qué mueve a pedir los tres panes, o sea, la Trinidad? La respuesta del predicador incluye modulaciones sobre un fondo común. Este fondo común es el deseo de felicidad o, en tono menor, de un cierto gozo, que, según los casos, puede adquirir distintas formas concretas. Poseer la Trinidad significa saciar el deseo de felicidad que comparten todos los hombres. El texto más claro y explícito al respecto es la célebre carta a Proba ${ }^{63}$. En

56 Trin. $1,10,20$

${ }^{57} \mathrm{Al}$ respecto, es significativo que en la obra Enarrationes in Psalmos, la más amplia de todas, sólo aparezca 25 veces el término trinitas.

58 Utilizamos la fórmula habitual en la tradición católica (tratado de Deo trino), aunque no está en la jerga teológica del santo.

${ }^{59}$ En s. uirg. 39 cambia la interpretación porque sigue otra traducción. Ya no lee sólo: "ut contempler delectationem Domini", sino que añade: "et protegi templum eius". Otras variantes en en. Ps. 127,9;143,10, s. 337,2;216,1; ep. 130,8,15. En en. Ps. 26,2,6 se fija en domo domini contraponiendo la casa (morada fija) a tabernaculum (tienda), morada pasajera en tiempo de guerra.

${ }^{60}$ De la función del Espíritu en la oración nos ocupamos con cierto detenimiento en el artículo citado en nota 1 .

${ }^{61}$ Así en qu. eu. 2,21; 105 A,1; ep. 130,8,15. Aunque sin olvidar advertir que se trata de una sola sustancia, de igual naturaleza porque da por hecho que no le daría un pan de trigo blando, otro de trigo duro y otro de centeno (cf. s. 105 A,1).

62 Cf. ep. 130,8,15. Se sirve de un "quizá".

${ }^{63}$ Cf. ep. 130,4,9-5,11. 7,14. 9,18. 13,24. 14,27. 
los demás, ese deseo y necesidad de felicidad va asociado a otros objetivos como la vida espiritual del cristiano y la actividad apostólica ${ }^{64}$. Comprender la Trinidad aporta el consuelo que necesita el fiel que, perdido en medio de los afanes de esta vida, se convierte a Dios, abandonando sus antiguos placeres. Mas, para seguir con vida, necesita una saludable instrucción espiritual que incluye el conocimiento de la Trinidad. El gozo interior que tal conocimiento procura compensa la renuncia a las satisfacciones de antes y permite a la vida espiritual seguir su desarrollo ${ }^{65}$. En otra interpretación el amigo que llega de viaje es el hombre fatigado por no haber hallado aún la verdad que, escuchada y puesta en práctica, puede hacerle feliz, verdad que solicita al cristiano. Una vez conseguidos los tres panes, es decir, una vez alimentado con la Trinidad, el que los pidió tendrá de qué vivir él y con qué alimentar al huésped. El pan es la Trinidad: "Alimento y pan eterno es el Padre, el Hijo y el Espíritu Santo. Aprende esto tú y enséñalo. Vive tú de él y alimenta al otro. Dios que es quien da, no puede darte cosa mejor que a Sí mismo"66. El sentido apostólico que advierte el predicador en la parábola se refuerza todavía más con estas palabras: "No temas que venga un peregrino de viaje; más bien, recíbelo y hazlo miembro de tu familia. No temas tampoco que se acaben tus provisiones. Ese pan, en vez de terminarse él, terminará con tu indigencia. Es pan, y es pan, y es pan: Dios Padre, Dios Hijo y Dios Espíritu santo"67. El motivo de que el Señor propusiese esa parábola fue infundir al fiel la seguridad de que recibirá lo que pide ${ }^{68}$.

Ambos aspectos son importantes en cuanto que recogen dos aspectos esenciales de la vida cristiana: el personal y el social. En el plano personal, la Trinidad se presenta como fuente de satisfacción y de gozo, alternativa a otros placeres y gozos con los cuales es imposible que pueda convivir, por lo que el hombre tiene que abandonarlos cuando se vuelve a la Trinidad. Nada extraño; detrás de esta concepción están dos conceptos que el santo ha puesto bien de relieve en la carta a Proba: primero, que el objeto de la oración del fiel cristiano no ha de ser otro que la bienaventurada, y luego, que la felicidad es inseparable de la posesión de Dios. Y por tratarse del Dios cristiano, de la posesión de la Trinidad. Esta misma concepción subyace al aspecto social, en este caso, la acción evangelizadora. Esta incluye

\footnotetext{
${ }^{63}$ Cf. ep. 130,4,9-5,11. 7,14. 9,18.13,24. 14,27.

${ }^{64}$ Este aspecto lo habían puesto de relieve ya Orígenes y san Ambrosio. Cf. nota 75.

${ }^{65}$ Cf. diu. $q u .2,21$.

66 S. 105,3,4

${ }^{67} S .105 .3,4$.

${ }^{68}$ S. 105 A, 1.
} 
la acción de dar de comer al necesitado y hambriento espiritual. De hecho, aunque impulsado por la parábola evangélica que está comentando, presenta a la Trinidad como tres panes. Y, en el contexto evangélico ${ }^{69}$, ese pan se identifica con el pan de cada día de la oración del Señor. El pan que los fieles piden para sí, el pan que es la Trinidad, es pan que deben compartir con los demás, sin temor a que les falte a ellos.

\section{d) La Trinidad, receptora de la súplica del fiel}

Que la Trinidad escucha las oraciones de los fieles era una verdad teológica indiscutible para san Agustín. Una vez admitido que las escucha el Padre y el Hijo, hay que aceptar que las escucha la Trinidad entera, es decir, las tres divinas Personas, en virtud del principio según el cual todas las obras divinas ad extra son comunes.

Por lo que se refiere a la oración que pide la Trinidad, ¿quién la escucha? Para saber lo que pensaba es útil volver a su interpretación de la parábola lucana. Si quien da los tres panes da (el conocimiento de) la Trinidad, procede averiguar quién es el que, siempre en su interpretación, los da. Al respecto, el exegeta no mantiene una línea definida. En un texto lo refiere a Dios "que es Trinidad", aunque recurriendo a una pregunta retórica ${ }^{70}$. En otro sermón lo refiere a Dios sin más explicaciones al indicar que "Dios, que es quien da, no puede darte cosa mejor que sí mismo"71. Pero, como está hablando de los tres panes, que son el Padre, el Hijo y el Espíritu santo, esto es, de la Trinidad, hay que pensar que con la palabra Dios se refiere aquí a la Trinidad misma. Sin embargo, un poco antes, en el mismo sermón, hace alusión a la familia que ya descansa con su Señor. Ahora bien, si en ese familia se cuentan Pedro y Pablo, no cabe pensar en otro Señor que en Jesucristo $^{72}$. Por otra parte, que piensa en Jesucristo aparece claro en otro texto en que invita a pedir los tres panes, porque el que los da no duerme

${ }^{69}$ La parábola sigue inmediatamente a la enseñanza del Padrenuestro por parte de Jesús.

${ }^{70}$ S. 105 A (Lambot 1),1: “¿Dios, que es Trinidad, no se dar a sí mismo si lo pedimos?”

${ }^{71} \mathrm{~S}$. 105,4. A Dios mismo vuelve a referirse en qu. eu. 2,21 al interpretar la parábola en el sentido de que, aunque falte un hombre que predique la Sabiduría (el conocimiento de la Trinidad), la recibe de manos de Dios mismo.

${ }^{72}$ Cf. s. 105,3; cf. también qu. eu. 2,21. El texto de la parábola ofrece una dificultad: en ella, el amigo que ya está descansando no quiere levantarse para dar los panes. Ante este hecho, al santo le gusta contraponer ese amigo holgazán a Dios o al Señor resaltando tanto que él sí quiere dar, aunque sólo al que le pide, como que él no duerme (en. Ps. 102,10), y, al mismo tiempo, indicando que en ningún modo hay que pensar que el Señor alabara el comportamiento de aquel amigo, sino que lo uso sólo como una semejanza (cf. en. Ps. 57,7). 
ya. De hecho, cuando se le ora no se le molestaría como a uno que estuviese dormido, puesto que no dormirá ni dormitará el guardián de Israel (Sal 120,4). Es cierto que murió a fin de formarse una esposa de su costado, pero también lo es que, resucitado de entre los muertos, ya no muere más, pues la muerte ya no tiene dominio sobre él (Rom 6,9 $)^{73}$.

\section{Conclusión}

Una vez roto el velo del templo con la muerte de Cristo, se abre definitivamente el tiempo de la nueva Alianza. Los cristianos aprendieron a leer el Antiguo Testamento desde la revelación aportada por la vida y enseñanzas de Jesús. San Agustín expresa la razón de ese proceder: "El Antiguo Testamento oculta el Nuevo y el Nuevo revela el Antiguo"74. La revelación fundamental tenía a Dios mismo como objeto: el Dios único de la tradición judía se manifestaba existiendo en tres personas iguales, pero distintas. Como no podía ser de otra manera, el santo lo aplicó también el tema de la oración. Por ello, el Dios al que oraba y al que exhortaba a orar era el que, sin dejar de ser el Dios único del salmista, se había revelado como Trinidad. Y, consecuentemente, él trató de comprender y enseñar la dimensión trinitaria que necesariamente había de tener la oración cristiana, al estar dirigida al Dios ya conocido como Trino. Una forma consistió en relacionarla con cada una de las Personas divinas; otra, en relacionarla explícitamente con la Trinidad en sí misma, esto es, con las tres divinas Personas en su conjunto. Sólo de este segundo aspecto nos venimos ocupando en estas páginas.

Pero, aunque, con la revelación neotestamentaria, el concepto de Dios en cuanto ser supremo, principio y fin de cuanto existe, se había modificado en el sentido de incluir las tres Personas, bajo el Dios al que la Iglesia y los fieles en particular se dirigían en su oración, el santo solía entender sólo una Persona, normalmente el Padre, con menos frecuencia el Hijo y raramente el Espíritu santo. Aunque las personas son tres, la oración se dirigía sólo a una de ellas. En este proceder san Agustín sigue la pauta de la Escritura: como esta en ningún caso presenta a la Trinidad como destinataria de la oración cristiana, tampoco él la dirige nominalmente a ella. Aunque

${ }^{73}$ Cf. en. Ps. 102,10. Al respecto es significativo que no diga que duerme con su familia, sino que descansa con ella (s.105,3). Cf. también ep. 130,8,13: “... el que no puede dormir y hasta nos despierta, cuando dormimos, para que pidamos".

${ }^{74}$ Cf. s. 160,$6 ; 300,3 ;$ en. Ps. 105,36 ; ciu. 16,26 , etc. 
la historia de la salvación es obra unitaria de las tres divinas Personas, el hombre la percibe segmentada, asociando, por simple atribución, a cada una de ellas una función específica, que da razón de que la oración se eleve explícitamente a una u otra Persona divina y no a las tres en su conjunto. Pero una vez constatado y tratado de explicar lo que afirman los textos, hay que añadir: aunque no presente a la Trinidad como destinataria de la oración de los fieles,-dejamos de lado ahora las doxologías trinitarias-, al santo no podía quedarle duda de que efectivamente lo es. Si, según enseñanza suya, el fiel cristiano ha de pedir la Trinidad, ¿a quien la ha de pedir sino a ella misma? Admitido lo uno, no cabe sino admitir lo otro.

De forma explícita, san Agustín invita a los fieles a desear y pedir la Trinidad misma, concibiendo ya el deseo mismo como una forma de petición. En cuanto al deseo de ella, sostiene, como ya indicamos, que es la Trinidad misma la que lo suscita en el fiel. El apoyo bíblico lo tiene en Jn 14,8, al precio de interpretar en cláve trinitaria el deseo que Felipe manifiesta a Jesús de que le muestre al Padre. En cuanto al pedir la Trinidad, encuentra apoyo en Lc 11,5, sirviéndose de una interpretación alegórica, ya tradicional ${ }^{75}$, según la cual pedir los tres panes equivale a pedir la Trinidad. La base antropológica del desear y del pedir la Trinidad está en el ansia de felicidad. El hombre aspira a la felicidad, que san Agustín considera inseparable de Dios que, según la fe cristiana, existe en la trinidad de Personas. Al considerar la Trinidad como el único objeto del frui o, lo que es lo mismo, el único capaz de procurar el auténtico gozo, era lógico que juzgase que sólo quien la posea podrá ser feliz. Un poseer que equivale a entrar en relación profunda con ella, con cada una de sus tres divinas Personas. Poseerlas a ellas basta, pero es imprescindible.

Para concluir, señalamos que san Agustín sitúa el desear y pedir la Trinidad también en contexto pastoral. En realidad no hace sino seguir la pauta de la parábola lucana; en ella quien pide los panes no los pide para sí, sino para otro, para un amigo que ha llegado de viaje: "préstame tres panes, porque ha llegado de viaje a mi casa un amigo mío y no tengo qué ofrecerle" (Lc 11,5-6). Por tratarse de un amigo, con el que se suele mostrar generosidad, el santo presupone que el que pedía para el amigo tampoco tenía para sí, pues en este caso hubiera dado lo que poseía al amigo, aunque se hubiera quedado él sin nada. Este presupuesto aparece en frases

${ }^{75} \mathrm{Tal}$ interpretación aparece ya en Orígenes (In Lc fragmentum, SCh 87,527) y de forma menos clara en san Ambrosio (Expositio euangelii sec. Lucam7,87). Más tarde en la Vida de los Padres del Jura (Vita uel regula sanctórum Patrum...iurensium abbatum, praef., SCh 142, 247). 
como "en nuestra necesidad, recibimos para él y para nosotros"76 o "tendrás con qué vivir tú y con qué alimentar al otro"77. Al señalar que fueron los dos los beneficiados de la súplica, el santo dejan entender que la necesidad alcanzaba también a nivel personal al que pedía los panes. El orden de los beneficiados cambia de un texto a otro, pero el del segundo texto parece obedecer sólo a una variatio literaria; el orden objetivo en que piensa el santo es el primero. Así aparece en este otro pasaje: "al querer enseñar, te ves obligado a aprender, y la vergüenza que te hace sentir quien no encontró en ti lo que buscaba, te fuerza a buscar para merecer encontrar"78. Estas palabras contienen una aplicación al ámbito pastoral del contenido de la parábola. Primero en forma de constatación: a menudo, uno solo toma conciencia de la propia pobreza cuando tiene que dar; luego como invitación: si a uno le piden y no tiene que dar, en vez de renunciar a dar porque no tiene, ha de pedir para poder dar. La acción pastoral se convierte en motivo e impulso para la oración de petición. Por eso mismo, la acción pastoral se convierte en fuente de enriquecimiento de quien la realiza. Cuando el pastor ha de atender exigencias de otros, si estas son más altas que las propias, él mismo acaba haciendo suyas esas exigencias y, consiguientemente, enriqueciéndose ${ }^{79}$.

Manteniéndose dentro de la misma imagen alimentaria, el predicador presenta el conocimiento de la Trinidad como alimento tanto para el que quiere acceder a la fe como para el que ya está dentro de ella. Para el primero, es alimento sustancioso, capaz de nutrirle adecuadamente cuando busca apacentar su espíritu con la verdad cristiana. Para el segundo, alimento deleitoso que compensa por las renuncias que le exige la vida cristiana misma ${ }^{80}$.

\footnotetext{
${ }^{76}$ S. 105,2.

${ }^{77}$ S. 105,4.

${ }^{78} \mathrm{Ib}$.

${ }^{79}$ Cf. s. 105,3.

${ }^{80}$ Cf. $q u . e u .2,21$.
} 